\title{
ARTE PÚBLICA E AS PAISAGENS PANDÊMICAS
}

\author{
Leandro Riente da Silva Tartaglia ${ }^{1}$ \\ Colégio Pedro II \\ leandro_rst@hotmail.com
}

\section{JUSTIFICATIVA}

O que justifica o fazer artístico? Tal questionamento emoldura a humanidade desde a sua aurora, a exemplo da arte rupestre. Uma retrospectiva histórica permite uma mirada de como a cultura de diferentes povos se manifestou, e ainda se manifesta, através da produção artística. Em pleno século XXI como podemos rever essa questão? Elementos tecnológicos que passam pela automação e a internet desafiam uma perspectiva de como traçar o futuro. De uma forma distópica, a pandemia se espalha rapidamente pelo planeta impondo uma nova relação das sociedades com a arte, a cultura e o espaço.

A configuração de paisagens pandêmicas nas cidades brasileiras tornou explícita a sua profunda desigualdade social, e no limite, a própria banalização da vida. Enquanto ruas ficaram desertas em plena luz do dia nos bairros de classe média e áreas nobres em virtude do isolamento social, um número incontável de favelas e periferias urbanas sequer apresentam o abastecimento adequado de água potável e redes de esgoto igualmente necessários para o combate ao vírus, de acordo com as normas internacionais de segurança sanitária. Diante desse abismo, um conluio desumano da classe política e setores empresariais promoveram um verdadeiro processo de desinformação sob a lógica da vitalidade econômica em detrimento da preservação da vida, deteriorando ainda mais as condições políticas e sociais no Brasil.

Como explicar tudo isso a uma criança de cinco anos? A arte surge como elemento pedagógico a partir da intervenção na cidade. Uma arte pública que promove a comunicação ao subverter a função dos objetos urbanos que se encontram pelos caminhos cotidianos. Arte que

\footnotetext{
${ }^{1}$ Professor do Colégio Pedro II - Unidade Tijuca II. 
ilustra e torna didática a crítica a uma sociedade que reage a ideias progressistas e duvida da ciência, ao mesmo tempo que menospreza toda sua riqueza cultural, reforçando de maneira hipócrita o racismo, a intolerância e a devastação ambiental. Uma arte que inunde de cores (sabores, sonoridades) e inventividade as cidades monocromáticas e desertas de esperança, ao mesmo tempo que seja capaz de nos lembrar que esta ausência, nos coloca na condição de meros reprodutores de objetos e tarefas. E, se possível, que consiga nos fazer olhar para o passado, a fim de não reproduzir os mesmos erros no futuro.

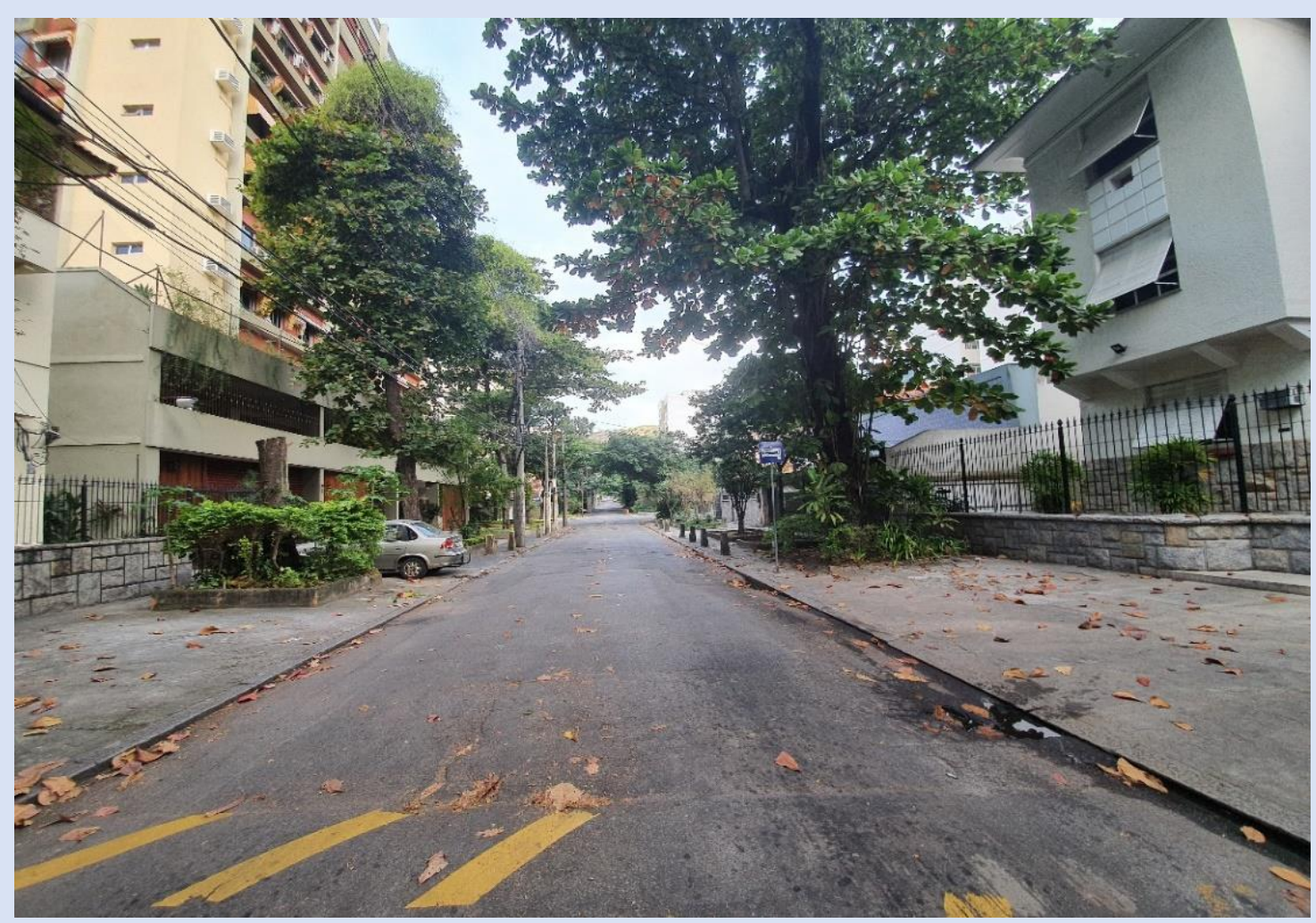

Ruas desertas durante o isolamento social - Grajaú - Rio de Janeiro.

(Foto: Leandro Tartaglia, 2020)

AO CITAR ESTE TRABALHO, UTILIZE A SEGUINTE REFERÊNCIA:

TARTAGLIA, Leandro Riente da Silva. Arte pública e as paisagens pandêmicas. Revista Ensaios de Geografia, Niterói, vol. 5, nº 10, p. 126-129, julho de 2020.

Submissão em: 05/05/2020. Aceite em: 03/07/2020.

Universidade Federal Fluminense, Niterói, RJ - Brasil 


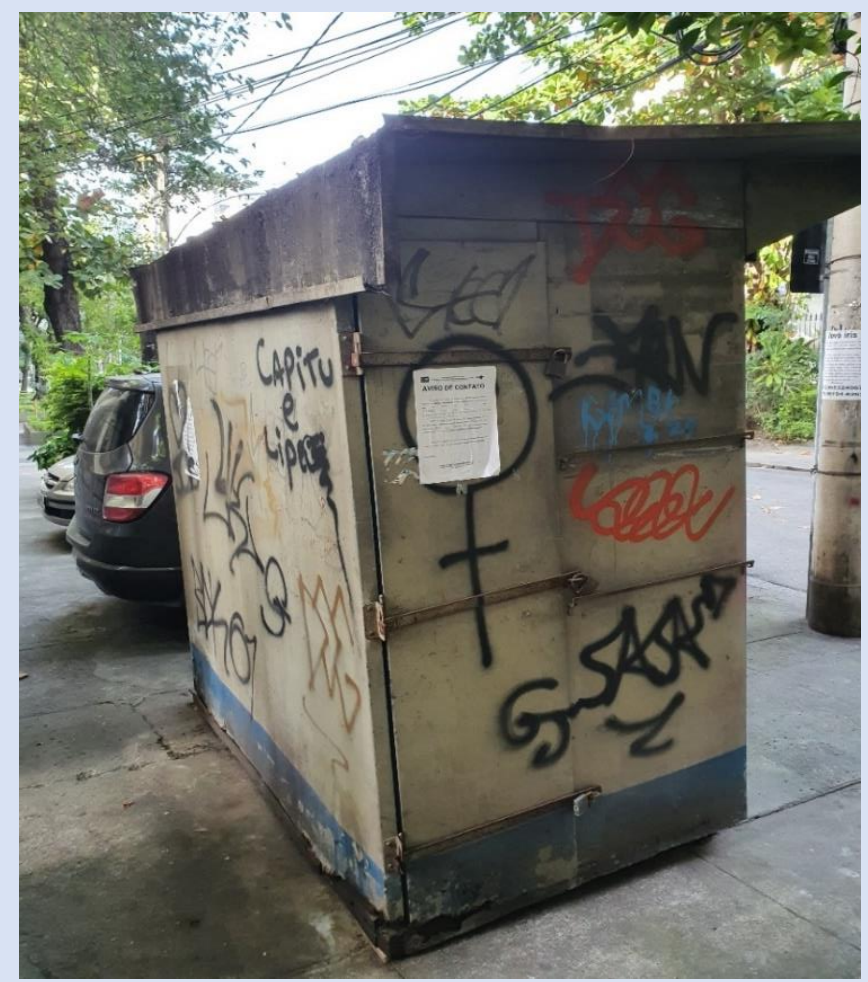

Banca de jornal abandonada (objeto urbano e o caminho cotidiano) - Grajaú - Rio de Janeiro. (Foto: Leandro Tartaglia, 2020)

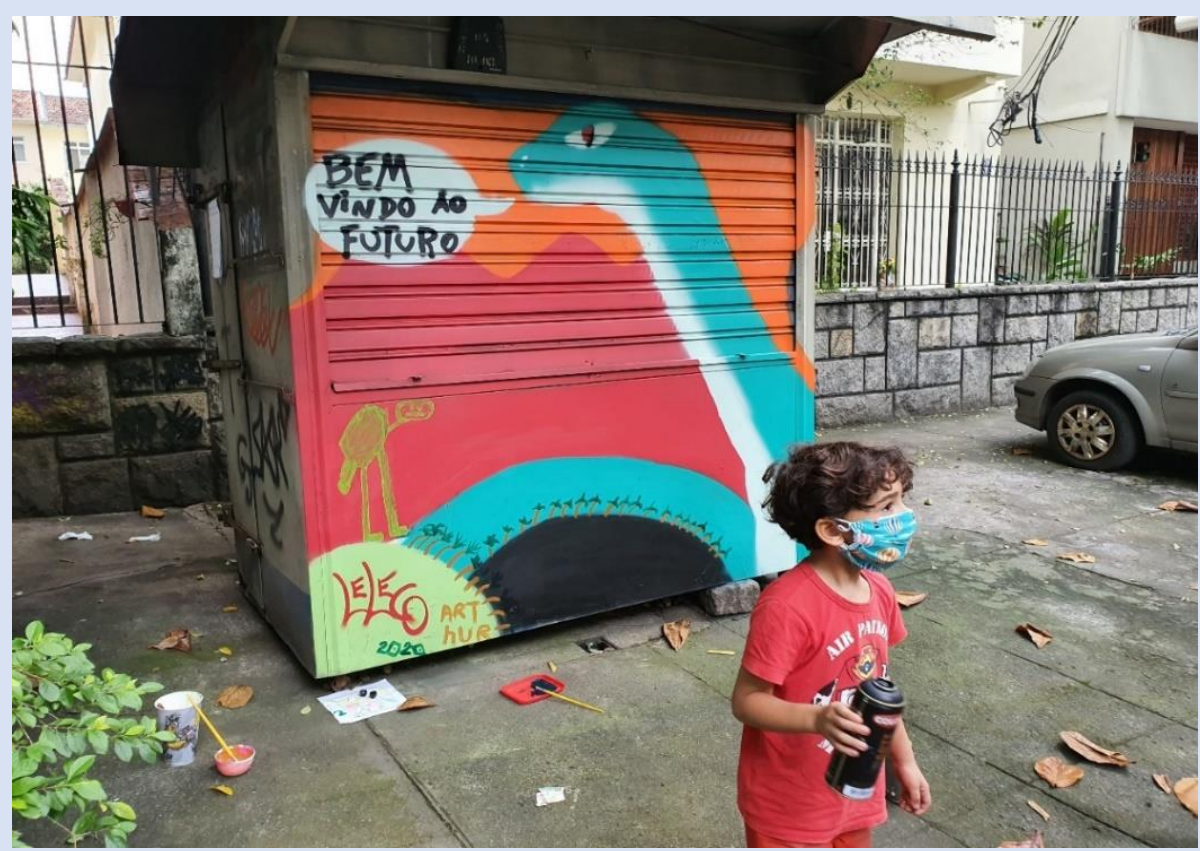

Intervenção e produção artística - Grajaú - Rio de Janeiro.

(Foto: Leandro Tartaglia, 2020)

AO CITAR ESTE TRABALHO, UTILIZE A SEGUINTE REFERÊNCIA:

TARTAGLIA, Leandro Riente da Silva. Arte pública e as paisagens pandêmicas. Revista Ensaios de Geografia, Niterói, vol. 5, nº 10, p. 126-129, julho de 2020.

Submissão em: 05/05/2020. Aceite em: 03/07/2020.

Universidade Federal Fluminense, Niterói, RJ - Brasi 


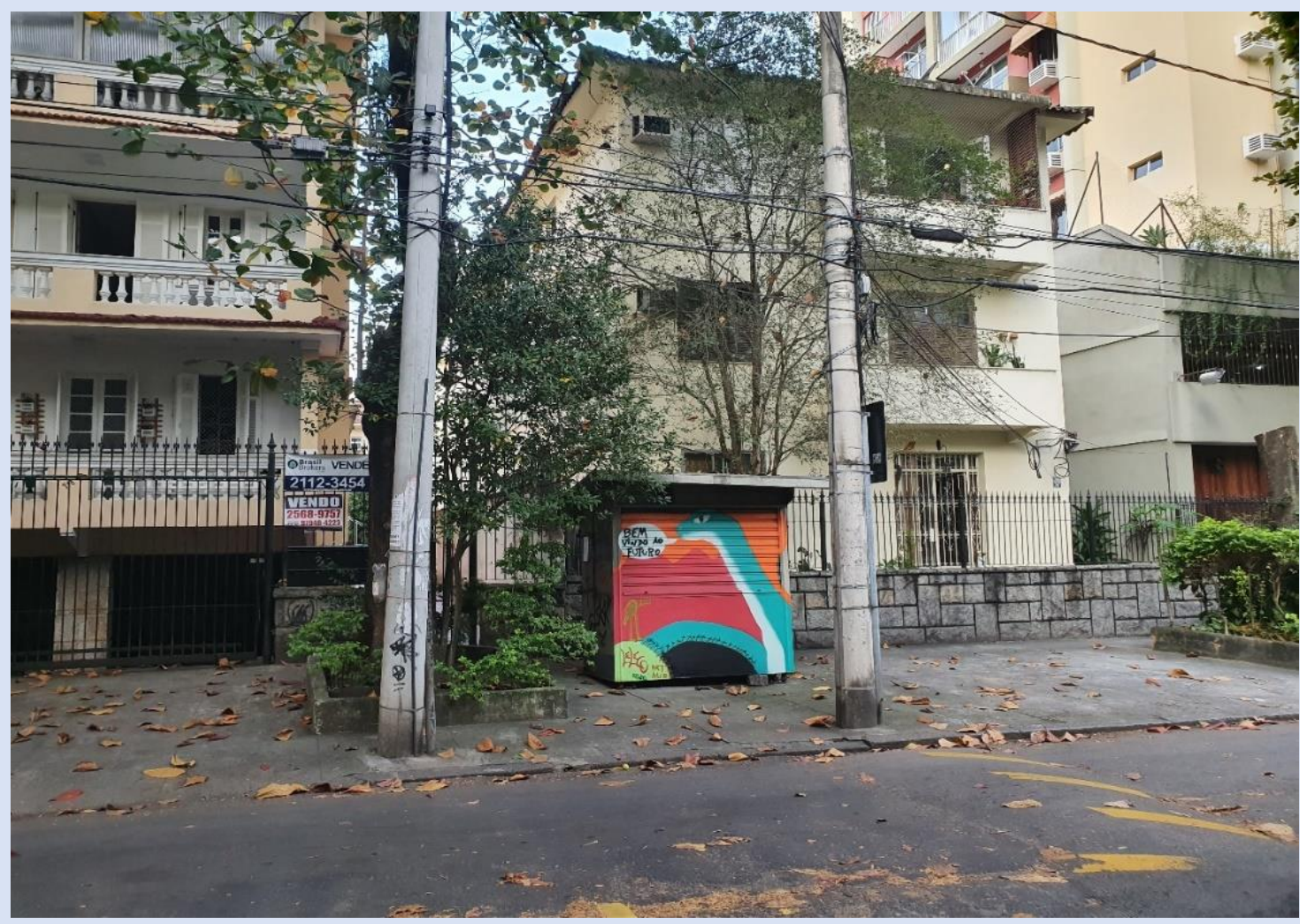

Arte pública como elemento pedagógico - Grajaú - Rio de Janeiro. (Foto: Leandro Tartaglia, 2020)

AO CITAR ESTE TRABALHO, UTILIZE A SEGUINTE REFERÊNCIA:

TARTAGLIA, Leandro Riente da Silva. Arte pública e as paisagens pandêmicas. Revista Ensaios de Geografia, Niterói, vol. 5, nº 10, p. 126-129, julho de 2020.

Submissão em: 05/05/2020. Aceite em: 03/07/2020.

Universidade Federal Fluminense, Niterói, RJ - Brasi 